\title{
Thierry Ozwald, Mérimée épistolier
}

\section{Michel Arrous}

\section{(2) OpenEdition}

\section{Journals}

\section{Édition électronique}

URL : http://journals.openedition.org/studifrancesi/5677

DOI : 10.4000/studifrancesi.5677

ISSN : 2427-5856

\section{Éditeur}

Rosenberg \& Sellier

\section{Édition imprimée}

Date de publication : 1 septembre 2011

Pagination : 433-434

ISSN : 0039-2944

\section{Référence électronique}

Michel Arrous, «Thierry Ozwald, Mérimée épistolier », Studi Francesi [En ligne], 164 (LV | II) | 2011, mis en ligne le 30 novembre 2015, consulté le 09 janvier 2021. URL : http://journals.openedition.org/ studifrancesi/5677 ; DOI : https://doi.org/10.4000/studifrancesi.5677

\section{Ce document a été généré automatiquement le 9 janvier 2021.}

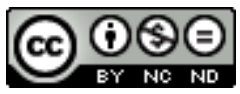

Studi Francesi è distribuita con Licenza Creative Commons Attribuzione - Non commerciale - Non opere derivate 4.0 Internazionale. 


\title{
Thierry Ozwald, Mérimée épistolier
}

\author{
Michel Arrous
}

\section{RÉFÉRENCE}

THIERRY OZWALD, Mérimée épistolier, Paris, Eurédit, 2010, 251 pp.

1 Heureuse idée que de regrouper sept articles, publiés entre 1990 et 2006, sur quelquesuns des aspects de l'épistolier prolixe que fut Mérimée. On saura gré à Thierry Ozwald d'avoir emprunté des pistes peu fréquentées par les admirateurs de cette «phénoménale» correspondance qui, pour une fois, n'est plus uniquement considérée pour sa valeur de témoignage, mais comme un contrepoint à l'œuvre du nouvelliste, aspect trop souvent négligé. Attentive, nuancée, et même subtile quand elle s'attache à en saisir la tonalité intime et la musicalité, l'approche choisie met d'abord en évidence la théâtralisation constante de l'écriture, quel que soit le registre; ensuite, la qualité du pacte établi avec le lecteur, dans une fidélité totale (ou presque) au code des bonnes manières. Adepte d'une civilité n'excluant pas l'humour, Mérimée pratique le lettre comme un libre entretien d'où est bannie la moindre platitude, même s'il s'agit du cas limite de la lettre officielle.

Dans la première partie est défini l'art de la lettre selon Mérimée, d'un point de vue moins stylistique que psychologique. Dans les pages enjouées adressées de 1844 à 1866 à la comtesse de Boigne se dessine un Mérimée attentif à la vie politique et mondaine, soucieux de mise en scène à travers des anecdotes piquantes et des portraits, sans jamais donner dans l'excès ni l'outrance. Un thème constant: une France déjà décadente dont il donnerait une vision «quasi gogolienne, prékafkaïenne». On sait que Mérimée n'est pas tendre pour la médiocrité contemporaine qu'il raille non sans désinvolture. Des pages sensibles sont consacrées à l'emprise du temps («Vieillir en écrivant, écrire en vieillissant», Gérontologie et société, septembre 2005). Pour ce «pauvre malade qui aime encore le monde», comme il l'écrit le 27 février 1870, l'écriture peut être une manière de conjurer le mal, mais surtout une épreuve et une preuve de volonté, «une sorte d'exercice spirituel» pour entretenir l'esprit critique en 
commentant la politique française et les relations internationales, sujet dans lequel il fait preuve de discernement, la chronique mondaine et littéraire - bien que vieillissant, Mérimée lit ses pairs et s'en entretient avec ses correspondants favoris. Et, par-dessus tout, il travaille et leur recommande le travail, sans jamais se départir de cette forme particulière d'humour qu'est l'autodérision. Cette pratique est analysée à partir d'exemples relevés dans le premier volume de la Correspondance générale, où serait déjà à l'œuvre une écriture dans laquelle percerait un autre moi, "coercitif et castrateur», voire «destructeur», un moi quasiment névrotique. Cette interprétation à peine avancée, Th. Ozwald, qui ne prétend d'ailleurs pas tenter une psychanalyse de Mérimée pendant les années 1822-1835, la nuance prudemment, car Mérimée se surveille, même quand il lui arrive de se confier. Sa protection, c'est l'humour, comme le montre sans cesse la «dimension extraordinairement et inépuisablement humoristique» des lettres de cette période. De nombreux exemples illustrent la pratique de Mérimée qui épingle, dénonce, démasque. Il est bien l'homme de la transgression, mais il n'est pas exact de dire que cette satire est toujours «tendre et attendrissante».

Dans la deuxième partie, l'étude sur «Mérimée dans l'Ouest de la France» mériterait d'être révisée et complétée car elle date de 1992. Th. Ozwald a privilégié les voyages d'inspection en Anjou, Touraine et Poitou, bien connus grâce aux publications d'Auzas, Mallion et Parturier mises à contribution, ainsi que les lettres à ces véritables amis que furent les architectes Joly-Leterme et Segretain. On regrettera que les débats et les rapports de la Commission des monuments historiques n'aient pas été exploités, ni certains articles de Mérimée. Au chapitre des amis, il n'y a pas que des architectes ou des archéologues, mais aussi et surtout deux figures centrales: Beyle et Tourgueniev. De l'étude centrée sur le dialogue avec Stendhal («Stendhal-Club», 1990), on dira qu'elle a mieux vieilli que la précédente tant l'auteur a pris soin de démonter les clichés et affirmations simplistes sur la parenté littéraire des deux hommes. Il s'agit de lire une correspondance incomplète puisque Mérimée a dit avoir brûlé les lettres de Stendhal il n'en reste que trois! L'historique de leur relation est retracé avec précision: sincérité des rapports et même complicité, comme le démontre le récit de la première entrevue avec Jenny Dacquin, réservé au seul Stendhal, les anecdotes paillardes, le débat à propos d'Armance et du «fantasme d'impuissance» qui est aussi celui de Mérimée. Il y eut sans doute entre eux bien des connivences et un compagnonnage littéraire, mais il nous semble que les malentendus se sont renouvelés après Armance, notamment avec Le Rouge et le Noir et la Vie de Napoléon. Quant à voir Stendhal en accoucheur de l'écrivain Mérimée, il y a un pas que Th. Ozwald se garde bien de faire. Et «HB»? La petite plaquette aurait mérité un détour plus appuyé car elle est évidemment une manifestation d'humeur. Ce De Amicitia se clôt sur l'évocation des «destins croisés de Mérimée et Tourgueniev», cas unique d'une «exceptionnelle fraternité en littérature» dont témoigne un non moins exceptionnel échange, soit quatre-vingt quinze lettres écrites entre 1867 et 1870. Correspondance construite en triptyque (politique, littérature, maladie), comme celle avec Stendhal, mais d'une toute autre nature puisque Mérimée - enfin! - lève le masque.

On trouvera en annexe l'étude intitulée «Croquis, esquisses et clichés: les Lettres d'Espagne de Mérimée» (Anales de filología francesa, Murcia, 2006). Dans ces lettres Th. Ozwald veut voir une préfiguration de la nouvelle épistolaire (L'Abbé Aubain) et repère, d'une manière plus convaincante, des liens avec l'œuvre passée et à venir. Leur trame romanesque serait déjà celle de Carmen, mais «à l'envers». Leur dimension anthropologique (enquête sur la superstition, les rites et la religion, le primitif) est 
justement soulignée car, s'il est vrai que Mérimée s'y livre à un véritable démontage du mythe espagnol, c'est pour mieux en retrouver les fondements.

5 Même s'il arrive à l'auteur d'esquisser des hypothèses de lecture parfois aventurées ou d'évoquer, trop rapidement à notre gré, la «stylistique du retrait» qui a pourtant à voir avec une pratique déceptive du récit, ce recueil est le bienvenu, car l'art épistolaire de Mérimée, reconnu dès longtemps et parfois au détriment de l'œuvre du nouvelliste, est enfin évoqué dans sa diversité. 